\title{
Baugruppen hermetisch versiegeln
}

U m hochwertige elektronische Baugruppen wie BGAs oder QFPs für die Industrieelektronik, KFZ-Industrie, Luftfahrttechnik und Medizintechnik zuverlässig zu schützen, empfiehlt der EMS-Dienstleister Heicks den Einsatz des Paryleneverfahrens.

Dieses Vakuumbeschichtungsverfahren (CVD-Prozess) bietet eine hohe elektrische Durchschlagsfestigkeit und isoliert die Bauelemente bzw. Baugruppen wirksam gegen Feuchtigkeit, Korrosion, aggressive Medien sowie flüssige Kohlenwasserstoffe (Benzin, Diesel, Glykol) und fungiert außerdem als Diffusionsbarriere gegenüber Gasen. Parylenebeschichtete Baugruppen bestehen auch die hohen Anforderungen eines Salznebelsprühtests.

Da mit dieser Versiegelungsmethode darüber hinaus tiefe und en- ge Spalten sowie Bauteilkanten (keine Kantenflucht) beschichtet werden können, erfüllt sie die Anforderungen der Militärspezifikation MIL I46058C. Erwähnenswert ist ferner, dass Parylenebeschichtungen auf senkrechten Flächen die gleiche Beschichtungsdicke wie auf waagerechten Flächen aufweisen und physiologisch sowie toxikologisch völlig unbedenklich (FDA Zulassung) sind. Sie enthalten keine Lösungsmittel oder Weichmacher und erfüllen somit die ständig wachsenden Umweltanforderungen (REACH, RoHS). Die Paryleneschicht wird üblicherweise in Schichtdicken zwischen $1 \mu \mathrm{m}$ bis $50 \mu \mathrm{m}$ aufgebracht. Die Temperaturbeständigkeit beträgt je nach der eingesetzten Paryleneart (N,C,D,F) zwischen $-190^{\circ} \mathrm{C}$ bis $+300^{\circ} \mathrm{C}$.

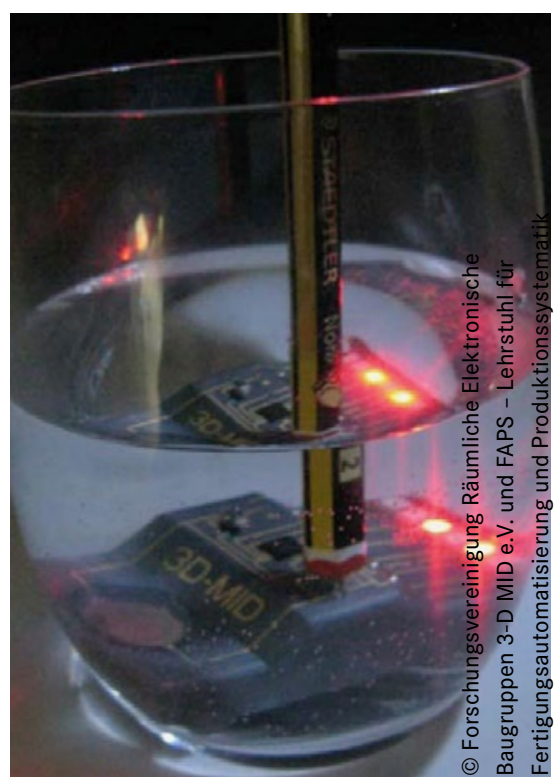

Parylenebeschichtetes 3-D MID

Demonstrationsauto im Wasserglas

Weitere Infos: Heicks Parylene Coating

$\mathrm{GmbH}$, Geseke, www.heicks.de

\section{Verkapselungsmaterialien für empfindliche Bauteile}

$H^{\mathrm{e}}$ enkel hat mit Loctite Eccobond UV9060F und Loctite Eccobond EN 3707F zwei neue Verkapselungslösungen auf den Markt gebracht, mit denen empfindliche Bauteile gezielt vor Umwelteinflüssen geschützt werden können. Beide Materialien wurden für Produktionsumgebungen mit hohen Durchsätzen entwickelt und härten unter UV-Licht in unter 30 Sekunden aus. Ein zweiter Aushärtemechanismus gewährleistet die vollständige Aushärtung von Bereichen, die das UV-Licht nicht erreicht. So verfügt Loctite Eccobond UV9060F über eine integrierte sekundäre Feuchtigkeitshärtung, während bei Loctite Eccobond EN 3707F eine sekundäre thermische Aushärtung stattfindet.

Der Einsatz dieser neuen Materialien empfiehlt sich insbesondere dann, wenn Conformal Coatings bzw. der Verguss einer gesamten Baugruppe vermieden werden sollen. Conformal Coatings wirken großflächig, zeigen meist jedoch eine Tendenz zum Sickern und zur Bildung von
Lücken; zudem bieten sie häufig nur unzureichenden Schutz bei Ecken oder komplizierten Geometrien. Neben den Vorteilen der schnellen Aushärtung und dem Schutz zeigen die beiden neuen Materialien beste Verarbeitungs- und Nachverfolgungseigenschaften. Sie eignen sich sowohl für die berührungslose Dosierung als auch für die herkömmliche Nadeldosierung und werden somit verschiedenen Produktionsanforderungen sowie Prozessen mit hohen Durchsätzen gerecht. Bemerkenswert ist schließlich der fluoreszierende Marker, der in beide
Verkapselungsmittel integriert ist und durch Schwarzlicht sichtbar wird, sodass das Bedienpersonal die zu beschichtenden Bereiche überprüfen kann.

Weitere Infos: www.henkel.com/electronics

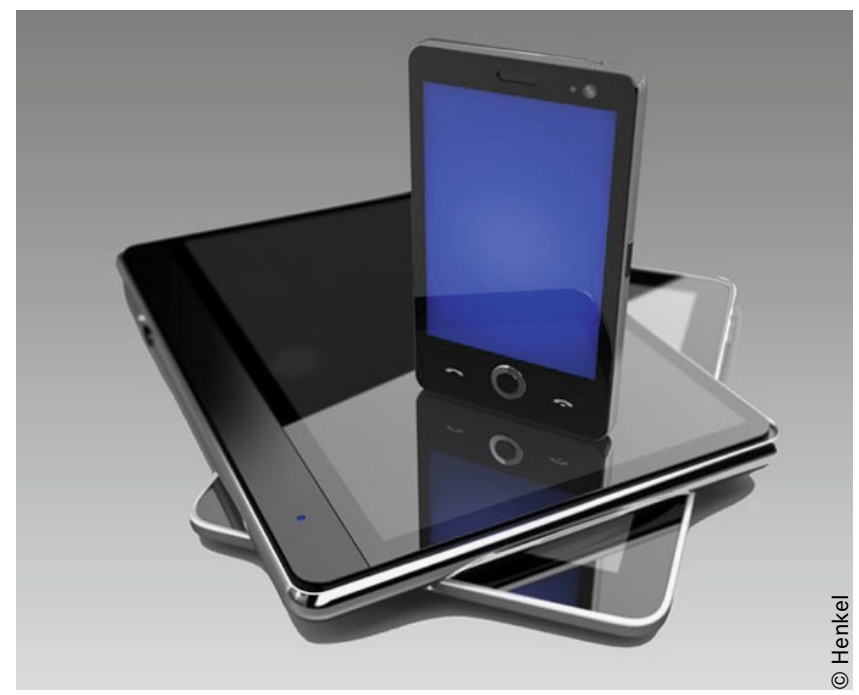

Loctite Eccobond EN 3707F bildet eine undurchlässige Barriere gegenüber potenziellen Umwelteinflüssen. 